\title{
Research Status and Countermeasures of photocatalyst in Water Pollution Treatment
}

\author{
Junye Li \\ Institute of Technology, East China Jiaotong University, Nanchang, Jiangxi, 330100, China \\ reparation of g-C3N4/TiO2 Photocatalytic Composite and Its Degradation of Printing and Dyeing Wastewater
}

\begin{abstract}
With economic development and population growth, the demand for fresh water resources is also increasing. However, affected by sewage discharge from industry, agriculture, mining and domestic, not only the ecological environment and natural resources are seriously damaged, but also the water resources available for people to drink are decreasing day by day. How to improve the water pollution treatment technology has become an urgent task. Because of the high cost and great limitation, the traditional treatment method has no significant effect in water pollution control. As an advanced oxidation technology, photocatalyst can effectively degrade pollutants in water pollution, and has a positive effect on improving water quality, protecting natural resources and maintaining ecological balance.
\end{abstract}

\section{Introduction}

Because of the need of production and life, people discharge more than 420 billion liters of sewage into natural water resources every year, accounting for 14 percent of the total drinking water of the earth. In China, about 50 billion liters of sewage flow to fresh water resources in nature every year. Nearly $90 \%$ of the sewage is discharged directly without any treatment. In order to reduce water pollution, China has adopted a variety of sewage treatment methods, which can be classified into the following three categories according to the principle of sewage treatment:

Table 1. principle of sewage treatment.

\begin{tabular}{|c|c|c|c|}
\hline method & principle & advantage & Insufficient \\
\hline $\begin{array}{l}\text { chemical } \\
\text { method }\end{array}$ & $\begin{array}{l}\text { Chemical } \\
\text { reactions, such } \\
\text { as oxidation, } \\
\text { electrolysis }\end{array}$ & \multirow{3}{*}{$\begin{array}{l}\text { It works When the } \\
\text { number and type of } \\
\text { pollutants are low }\end{array}$} & \multirow{3}{*}{$\begin{array}{l}\text { When the quantity, type and } \\
\text { organic matter of pollutants } \\
\text { increase, it is difficult to degrade } \\
\text { and the cost is high }\end{array}$} \\
\hline $\begin{array}{l}\text { physical } \\
\text { method }\end{array}$ & $\begin{array}{l}\text { Physical changes } \\
\text { such as } \\
\text { filtration, } \\
\text { adsorption }\end{array}$ & & \\
\hline $\begin{array}{l}\text { biological } \\
\text { methods }\end{array}$ & $\begin{array}{l}\text { Biological } \\
\text { metabolism }\end{array}$ & & \\
\hline
\end{tabular}

It is because of the obvious limitation of the traditional sewage treatment method that many researchers begin to turn their eyes to photocatalyst and achieve the purpose of rapid degradation of water pollutants by analyzing its oxidation principle and technology.

\section{Connotation and Principle of photocatalyst}

In the 1970s, photocatalytic technology developed rapidly, and the conversion of light energy to chemical energy can be realized by light source irradiation. In this process, the compounds are synthesized and degraded effectively. In general, the material molecules of photocatalyst include the following three structures: high energy conduction band, low energy valence band and band gap energy between them. When the sunlight energy in the material is larger than the band gap energy, the electrons in the low energy valence band will transition and form holes. When holes and electrons are in contact with water molecules and oxygen on the surface of the material, chemical reactions can occur, resulting in strong oxides that can rapidly degrade organic matter in water pollution, as shown below:

The reaction formula is as follows:

*Corresponding author's e-mail: 739960103@qq.com 


$$
\begin{gathered}
e^{-}+\mathrm{O}_{2} \rightarrow \cdot \mathrm{O}_{2}^{-} \\
\bullet \mathrm{O}_{2}^{-}+\mathrm{H}^{+} \rightarrow \bullet \mathrm{HO}_{2} \\
2 \mathrm{HO}_{2} \rightarrow \mathrm{O}_{2}+\mathrm{H}_{2} \mathrm{O}_{2} \\
\bullet \mathrm{HO}_{2}+\mathrm{H}_{2} \mathrm{O}+e^{-} \rightarrow \mathrm{OH}^{-}+\mathrm{H}_{2} \mathrm{O}_{2} \\
\mathrm{H}_{2} \mathrm{O}_{2}+e^{-} \rightarrow \mathrm{OH}^{-}+\bullet \mathrm{HO}_{2} \\
\mathrm{H}_{2} \mathrm{O}+h^{+} \rightarrow \mathrm{H}^{+}+\bullet \mathrm{OH} \\
h^{+}+\mathrm{OH}^{-} \rightarrow \bullet \mathrm{OH}
\end{gathered}
$$

Figure1.The reaction formula

( $\bullet 0_{2}^{-}$Representing superoxide radicals; $\bullet \mathrm{HO}_{2}$ Representing oxygen free radicals; $\bullet O H$ Representing hydroxyl radical)

\section{3 photocatalyst materials}

TiO2, ZrO2, Y2O3, ZnS, DdS and other oxides have a certain photocatalytic effect, which can degrade organic matter into renewable compounds, sometimes even into $\mathrm{CO} 2$ and $\mathrm{H} 20$. The Since researchers found that $\mathrm{TiO} 2$ electrodes can transform water molecules into $\mathrm{O} 2$ and $\mathrm{H} 2$ under the action of light and ultraviolet rays, $\mathrm{TiO} 2$ has attracted great attention in academia and related fields.

As a more mature semiconductor material in the research of traditional photocatalyst materials, there are many crystal forms $\mathrm{TiO} 2$, among which the main functions are rutile and anatase, the structure of which is shown in the figure:

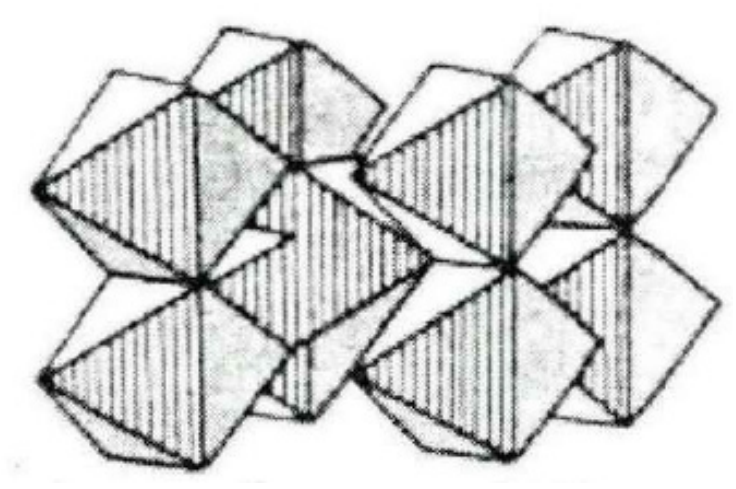

Figure2.Gold Red Stone

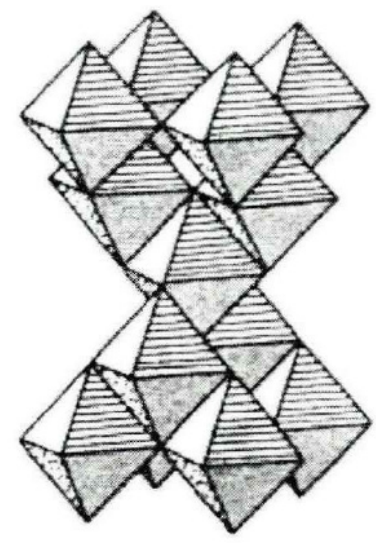

Figure3.Anatase type

The mass density of rutile type is $4.250 \mathrm{~g} / \mathrm{cm}^{3}$, band gap energy is $3.1 \mathrm{eV}$, anatase type $3.894 \mathrm{~g} / \mathrm{cm}^{3}$, band gap energy is $3.3 \mathrm{eV}$. Due to the weak adsorption capacity of rutile in oxygen, the photocatalytic efficiency is not very high. When rutile and anatase are mixed together, more electron-hole pairs will be formed, and the degradation rate of British and female will be significantly improved.

$\mathrm{TiO} 2$ will go through the following three steps in the process of photocatalysis:

First, $\mathrm{TiO} 2$ will absorb photons, and then realize the transition of electrons from valence band to conduction band to form carriers in semiconductors, that is, electron-hole pairs.

secondly, the carriers generated in the first step are transported to the surface of the $\mathrm{TiO} 2$ to form active components, so that the photocatalytic reaction can be carried out smoothly.

Finally, TiO2 redox reaction is realized on its surface.

moreover, the researchers have also developed a variety $\mathrm{TiO} 2$ nanocomposites to maximize the performance of $\mathrm{TiO} 2$ in the photocatalytic process. such as graphene/ $\mathrm{TiO} 2$ nanocomposites, as two-dimensional carbonaceous materials, graphene has excellent properties of absorbing, storing and transporting photoinduced electrons and is highly sensitive to holes and chemical doping. therefore, graphene is often used to improve the photocatalytic performance of $\mathrm{TiO} 2$ materials.

\section{Novel photocatalyst materials}

for improving the utilization effect of light energy, many researchers began to shift the center of gravity to visible photocatalysts, such as $\mathrm{Cu} 2 \mathrm{O} 、 \mathrm{Bi} 2 \mathrm{O} 3 、 \mathrm{WO} 3$, among which bismuth-based photocatalysts are more popular due to the characteristics of rich bismuth metals, low cost and easier to be excited by light sources. The valence band structure of common bismuth compounds is shown below: 


\begin{tabular}{cccc}
\hline chemical compound & $E_{\mathrm{CB}}(\mathrm{eV})$ & $E_{\mathrm{VB}}(\mathrm{eV})$ & $E_{\mathrm{g}}(\mathrm{eV})$ \\
\hline $\mathrm{Bi}_{2} \mathrm{O}_{3}$ & $0.16\left(E_{\mathrm{g}}=2.6\right)$ & 2.76 & $2.6 \sim 2.9$ \\
$\mathrm{Bi}_{2} \mathrm{WO}_{6}$ & $0.29\left(E_{\mathrm{g}}=2.6\right)$ & 2.89 & $2.6 \sim 2.7$ \\
$\mathrm{Bi}_{2} \mathrm{MoO}_{6}$ & $0.51\left(E_{\mathrm{g}}=2.4\right)$ & 2.91 & $2.3 \sim 2.7$ \\
$\mathrm{Bi}_{2} \mathrm{VO}_{4}$ & $0.34\left(E_{\mathrm{g}}=2.5\right)$ & 2.84 & $2.4 \sim 2.5$ \\
$\mathrm{BiOCl}$ & 0.14 & 3.64 & 3.5 \\
\hline
\end{tabular}

Figure4. The valence band structure of common bismuth-based compounds

As a semiconductor material with polymorphism, the band gap range of $\mathrm{Bi} 2 \mathrm{O} 3$ is between 2-3.9 eV with 6 medium morphologies :2 stable states and 4 metastable states. While $\mathrm{Bi} 2 \mathrm{O} 3$ can be used to degrade dyes in water under the diffraction of visible or ultraviolet light, the stability of $\mathrm{Bi} 2 \mathrm{O} 3$ materials is cross, and the practical application effect is not ideal.

Furthermore, the chemical and physical properties of the Bi2MoO6 are relatively good and have high applicability in photocatalysis, example conduction and gas sensing. Bi2MoO6, as a kind of $\mathrm{n}$ semiconductor, has high potential in photolysis of aquatic hydrogen and degradation of organic pollutants in water.By experiments, the researchers found that $\mathrm{Bi} 2 \mathrm{MoO} 6$ mainly rely on its morphology, size and microstructure to achieve photocatalytic performance. The hollow spheres in flower $\mathrm{Bi} 2 \mathrm{MoO} 6$ formed by solvent preparation have much higher photocatalytic performance than nanoparticles in Bi2MoO6. Therefore, researchers often use the Bi2MoO6 of hierarchical nanostructures or composite photocatalysts to inhibit carrier recombination, thus greatly improving the photocatalytic performance of $\mathrm{Bi} 2 \mathrm{MoO} 6$ materials.

As an important material of photocatalyst, bismuth oxide has many different practices.

\subsection{Solid phase method}

As a traditional powder preparation technology, the solid phase method needs to grind and exercise the reaction material fully, and then put a variety of reactants in the normal temperature environment to make them contact and react with each other.

\subsection{Gas phase method}

The method emphasizes that the reactant is in a gas state, through chemical or physical, etc., but should, and then obtain a desired product, which is usually a nanoscale crystal. Although the product is small and high purity, it is not easy to cause air pollution, but the process equipment, operation skills and other requirements are very high, the probability of successful production is relatively low.

\subsection{Chemical precipitation}

In this method, a certain number of precipitators and dispersants are evenly placed in the reaction solution. When the positive and negative ions meet and precipitate, the precipitate is filtered and calcined, and the necessary substances are finally obtained.

\subsection{Hydrothermal method}

The method is to use organic solution such as aqueous solution, ethylene glycol as the reaction solvent, first pour the reaction material into the solvent and pour the solvent into the special reactor. After high temperature and high pressure treatment, the reaction solution is poured out and loaded into the beaker, then vacuum drying, and finally the experimental product is obtained.

In addition to the above four methods, bismuth oxide has four different crystal forms, as shown below:

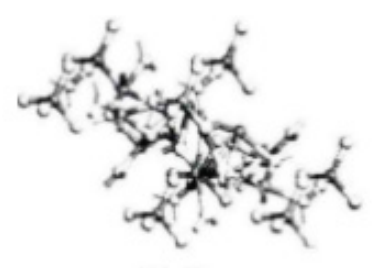

Figure5. $\alpha-\mathrm{Bi}_{2} \mathrm{O}_{3}$

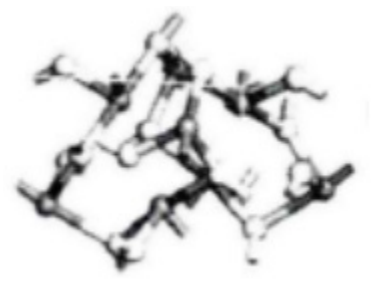

Figure7. $\gamma-\mathrm{Bi}_{2} \mathrm{O}_{3}$

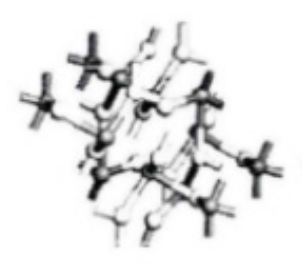

Figure6. $\beta-\mathrm{Bi}_{2} \mathrm{O}_{3}$

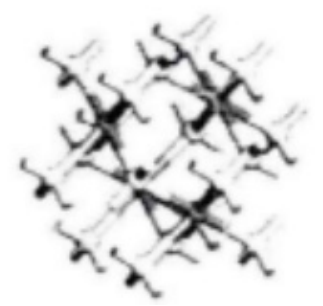

Figure8. $\delta-\mathrm{Bi}_{2} \mathrm{O}_{3}$
These four crystal forms have different properties because of their different structures, and they will change 
to varying degrees with the change of temperature.

Because bismuth oxide has good visible light catalytic function, it plays a great role in photolysis of water and purification of environment. Nevertheless, most of the valence bands of bismuth-based photocatalytic materials are composed of $\mathrm{O} 2 \mathrm{p}$ and $\mathrm{Bi} 6 \mathrm{~s}$, which have high charge fluidity and oxidation activity, which makes bismuth-based photocatalytic materials have an ideal development prospect. In addition, it has been accompanied by

\section{Conclusion}

Although photocatalyst has the advantages of low cost and wide degradation range, no release of harmful substances, simple reaction and easy operation, photocatalytic technology is not enough to produce the desired effect. There should also be a good treatment device, that is, photocatalytic reactor. Although many researchers have begun to turn to the study of photocatalyst water treatment, the design and development of photocatalytic reactor is not mature, resulting in the failure to achieve industrial scale production. Therefore, in the future study of water pollution treatment, photocatalyst will focus on reactor design to effectively supplement photocatalyst.

\section{Author:}

Junye Li (April 9,1984), female, native: Handan nationality, Hebei: Han nationality, master degree, lecturer, research field: water pollution treatment.

\section{References}

1. Gui, W.Ye, T.Chang, H.(2010)Design of Photocatalytic Treatment Device for Dynamic Circulating Sewage[J]. machine building.

2. Li, M.Y.Fang, G.L.Zhang, G.Wei, J.Zheng, G.(2018)Adsorption and photocatalytic properties of composites [J].Journal of Hebei University (Natural Science Edition).

3. Liu, D.X. (2015) Sewage Treatment in Oil Field[M]. China University of Petroleum Press.

4. Lu,Y.Qing,X.G.(2020)Advances in $\mathrm{TiO} 2$ Nanocrystalline photocatalysts in Water Pollution Treatment[J].Jiangsu Science and Technology Information.

5. Hao,J.Q.(2017)Preparation and visible photocatalytic properties of bismuth oxyates/new carbon materials photocatalysts[D]. Changchun University Of Technology.

6. Hao,Y.C.(2017)Preparation and Properties of New Bi-based photocatalysts and Their Composites[D]. Dalian Polytechnic University.

7. Chai,L.Y.(2018)Synthesis of novel electrocatalyst materials (molybdenum phosphide, bimetallic phosphides, sulfides) and their electrocatalytic
properties[D].Northwest University .

8. Fang,Z.Q.Liu,W.X.Chen,Y.R. (2003) Synthesis and Electrochemical Properties of Nano $\gamma \mathrm{MnO} 2-$ - of New Oxygen Electrostatic Catalyst Materials[J].Power supply technology.

9. Li,C.Y.(2012)Controllable synthesis of novel semiconductor photocatalysts and preparation of semiconductor-porous carbon composites[D].Northeast Forestry University .

10. Zhao.F.F.(2019)Preparation and properties of rare earth upconversion luminescent materials and novel semiconductor nanocomposite photocatalysts[D]. Shanghai University. 